\title{
Museum of Nias Earthquake (Vernacular Architecture)
}

\author{
Oscar A. Halawa ${ }^{*}$, Nelson Siahaan ${ }^{1}$ \\ ${ }^{1}$ Department of Architecture, Faculty of Engineering, Universitas Sumatera Utara, Medan, Indonesia
}

\begin{abstract}
Museum of Nias Earthquake is about a place to reintroduce local wisdom from Nias Island that related to their history and traditional building technology in response to earthquake disasters, with the aim of education and tourism. Nowadays, modern civilization marginalized a local culture. Vernacular themes are a solution in presenting the results of local-themed design. It will become an example of how to apply the local wisdom in contemporary building design, with the aim of reintroducing local sense. To achieve a vernacular theme, it started by using local materials, abstraction of local traditional houses, application of symbols and meanings from traditional building cosmology, and using observation and literature methodology. The result of this design is to meet the community needs for tourism objects that have a locality feel in Gunungsitoli City, Nias.
\end{abstract}

Keywords: earthquake, local wisdom, museum, tourism, vernacularism.

\section{Introduction}

Indonesia as the largest archipelago country in the world has the most extensive coastal line as well. The state has many cultures, traditions, and ethnicity that spread over 13,487 islands and one of them is The Nias Islands. This small archipelago located on the western tip of Sumatra Island has an area over $5,625 \mathrm{~km}^{3}$ and a population of nearly 900,000 . The livelihoods on this island rely heavily on the agricultural sectors, such as rubber, coconut, and coffee, etc. Farm sector, such as chickens, pigs, buffalo, etc. Their ancestor has legate local wisdom regarding an earthquake disaster in constructive ways. Their traditional houses are built to respond to this type of tragedy regarding structure. Now, the homes can survive from many earthquakes until today. The people still adhere to their existing traditional law. But the local knowledge in building structure side has been dramatically eroded by the growing modernization trend among the people of Nias. Their buildings no longer apply the local wisdom. Even though in many studies, their traditional houses have an above-average score concerning earthquake-resistant.

\footnotetext{
*Corresponding author at: Department of Architecture, Faculty of Engineering, University of North Sumatra, Perpustakaan Street, J07 Building, Medan, 20155, Indonesia.

E-mail address: oscarhalawa@gmail.com
} 


\section{Literature Review}

\section{Museum}

The general understanding of the museum is a building that displayed a collection of artifacts, historical objects or art objects for conservation, preservation, tourism and education purposes. A museum is a non-permanent, non-profit institution, but serving the public in many ways. A museum has the task of obtaining, storing, carrying, introducing and exhibiting its collection, for knowledge, education, tourism and become a human proof with its environment. Before the 20th-century, museums often focused only on maintaining collections inside. However, in the 20th-century, people began to realize that the guarding function didn't have to dominate. Then, things change architecturally. The increasing needs lead to the expansion of museum functions. Modern museums now provide public service spaces, such as educational workshops, rest areas, cafeterias, sales venues, multipurpose rooms, libraries, bookstores, etc. But at the same time, these spaces separate from the museum's main exhibition hall [1].

\section{Vernacular Architecture}

Rudofsky introduced the term "vernacular" in 1964 in an architectural exhibition entitled "Architecture Without Architect" at the Museum of Modern Art (MoMA). Vernacular syllable originally derived from the word "Verna" (Latin's) which means domestic, indigenous, native slave or home-born slave and then selected by Rudofsky as a term that classifies the local architectures around the world. The key elements that indicate vernacular architecture are; traditional self-built and community-built buildings, earlier building types, the design of environmental and cultural contexts, ecological conditions, natural material resources, structural systems, and technologies have a bearing on architectural form. Many aspects of social structure, belief systems, and behavioral patterns strongly influenced building types. Their functions, and meanings, dwelling, and other buildings, utilizing traditional technology, related to their environmental context and available natural resources, and architecture vernacular are built to meet specific needs in society [2].

\section{Vernacular of Nias Island}

The inhabitants of this island refer themselves as "Ono Niha" which means Nias people, which by some anthropologists believe they are one of the earliest Austronesian-speaking families from somewhere in Asia continent [3]. In the context of architecture, local wisdom on this island can generally be summarized by their cosmology terms. Their cosmology understood that life consisted of three worlds. The upper world (heaven), the human world and the underworld (hell). People of Nias are also heedful to their surrounding environmental conditions. Disasters that always happen, such as earthquakes and tsunamis, encourage people to think about how to respond this by applying the cosmological philosophy. 
The connection between the underworld, the human world, and the upper world is a manifestation about cosmology-beliefs among the people of Nias. A requirement for the creation of welfare in their lives and then embodied in the form of architecture as one of the vessels to apply those values. Every village in Nias is like an artificial world built on their cosmological philosophy. The megalithic culture that has existed since ancient times is a result of architectural and organizational concepts. One characteristic of megalithic culture is the existence of three gods (upper, middle and lower worlds) between the macrocosm and the microcosm. In Nias, it is understood the concept of three gods, between "Lowalangi" and "Laturedano" as the second supreme deities. Lowalangi is the ruler of the upper world (heaven) and Laturedano as the ruler of the underworld (hell). There is also the third god, "Silewe Nazarata" as the god of liaison between the upper world and the underworld (Figure 1) [4].

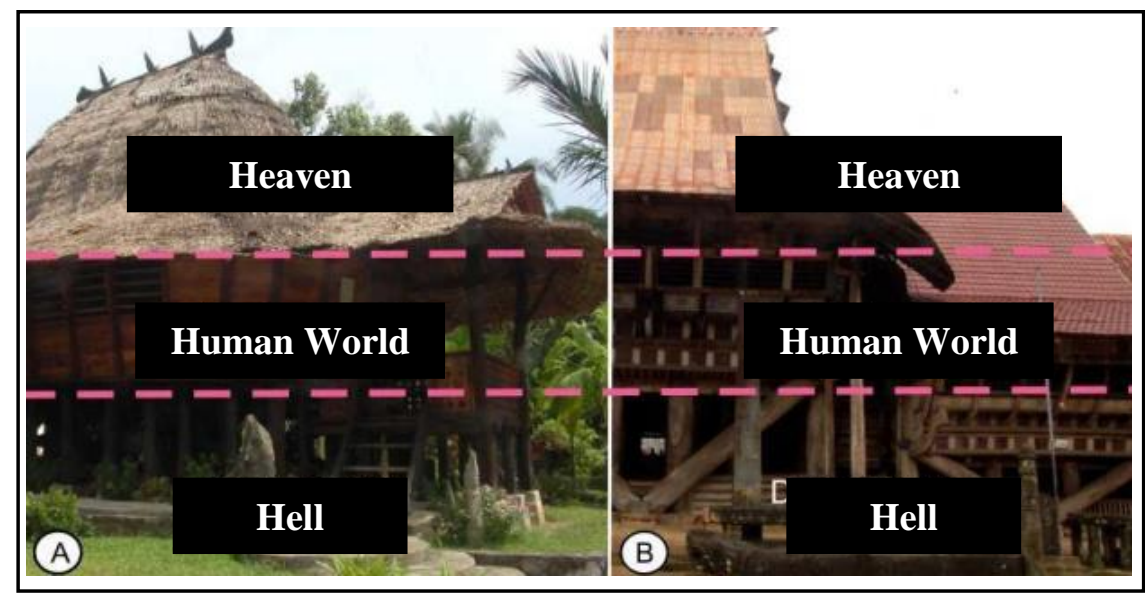

Figure 1. The Cosmology of Nias Traditional Houses, North (A) and South (B)

(Source: Google.com)

\section{Methodology}

During site selection, the types of issues and potential sites are assessed; accessing, utilities, land use, site orientation, site outlook, site topography, and site feasibility. The first step of the observation method is carried out with a field survey, collecting raw data, identifying problems and potential that exist on the site. Data is tangible as notes, schematic drawings and media files (photos and videos). Then the literature method is done by collecting data from literature books and scientific journals. The results of this method are primary and secondary data, which are the materials for later analysis.

Primary data are all the data that related to physical data on site. These data can be both qualitative and quantitative data way. Secondary data are data that obtained directly, without conducting surveys or direct observations, also qualitatively and quantitatively. This data comes from the literature study, and then in the next stage, all these data are analyzed by using relevant theoretical studies. 


\section{Result and Discussion}

Project site located in Nias Island, Gunungsitoli City, North Sumatra, Indonesia, precisely on Kartini Street. The site is $16,000 \mathrm{~m}^{2}$ full or around 1.6 hectares. Existing location functioned as a family burial place, then assumed as vacant land and ready to design both concerning the legality of administration and finance (Figure 2).

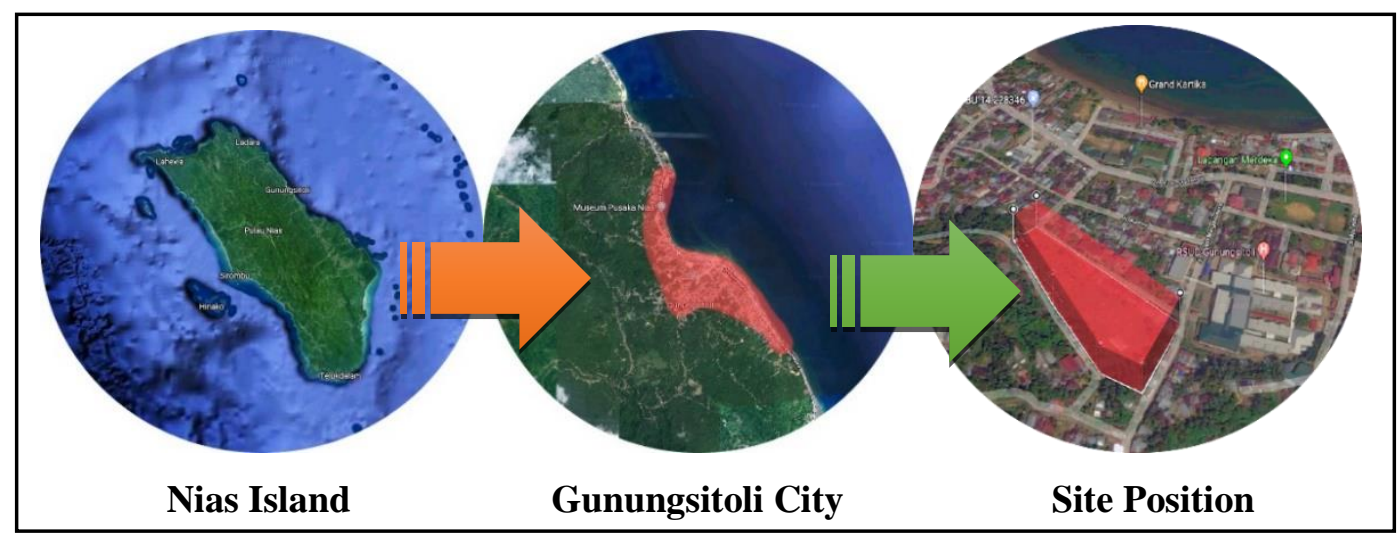

Figure 2. Project Location

\section{Main Concept}

The Museum of Nias Earthquakes has four main concepts, namely; Traditional Nias Traditional Houses. The basic idea is taken from Nias traditional houses, especially from the south side, as the source of vernacular architectural themes. This design refers to reflective elements and typical forms that exist in conventional homes. The concept reflects the belief in religious terms, adaptation to nature and local wisdom (Figure 3).

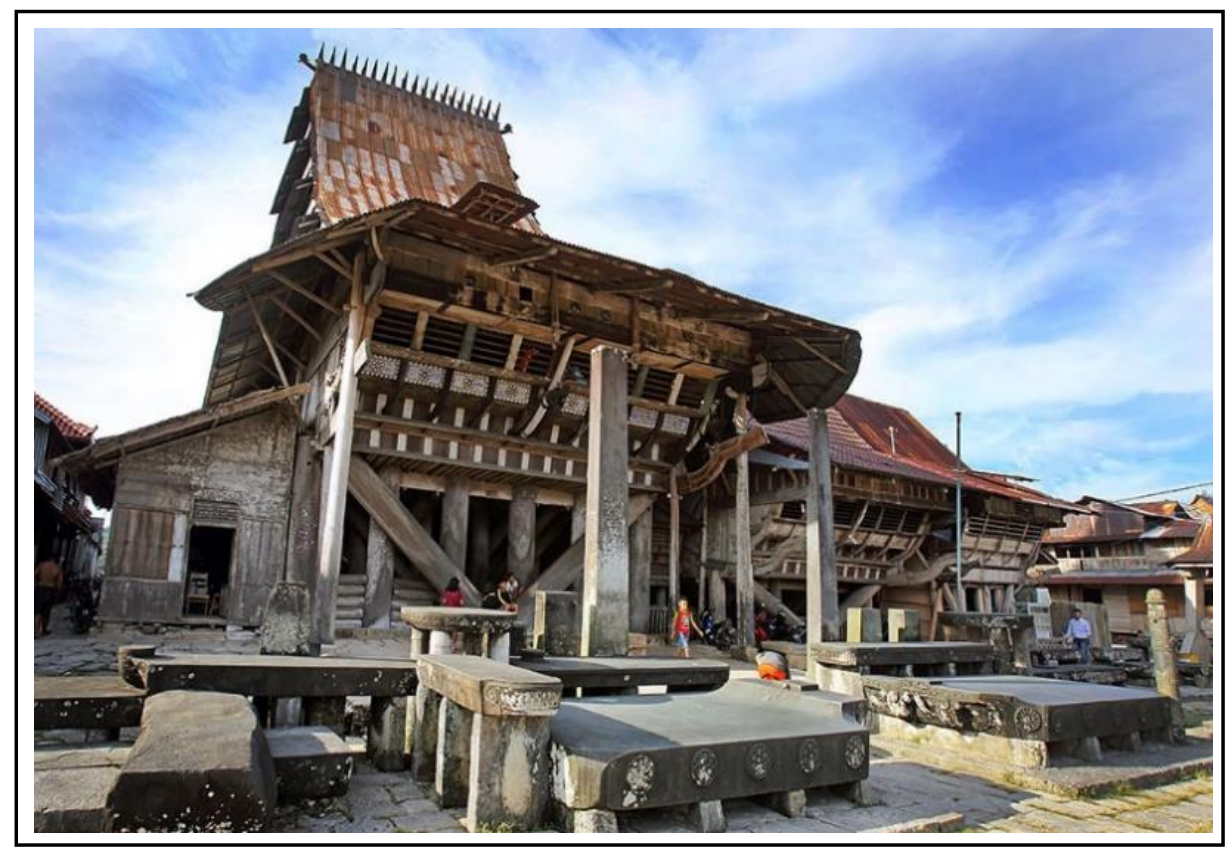

Figure 3. South Nias Traditional House

(Source: Museum-nias.org/arsitektur-nias) 
Story Telling. The concept to present the contents of the museum will be in the form of the space sequences like a story, regarding the occurrence of earthquake disasters that occur by dividing the space zones based on the theme of the stories raised into each space. This concept is reflected by a unique design in each room that each has a specific idea with the aim that visitors will be able to feel the situation that occurs when a disaster happens. Public Park. The Nias Earthquake Museum has a concept as a public space, can be a park, green open space and so forth that can be used by the community at any time in response to the urban and urban tourism context. The concept of public park combined with the idea of escape building, where the public park will become the assembly point for the evacuation route. Escape Building. The museum design will anticipate the possibility of recurrence of the same disaster. The central concept is to make the museum complex as well as the main building in it as an evacuation center.

\section{Zoning Concept}

Zoning is based on Gunungsitoli City regulation rules. The site is divided into several complementary parts so that there are clear boundaries (Figure 4).

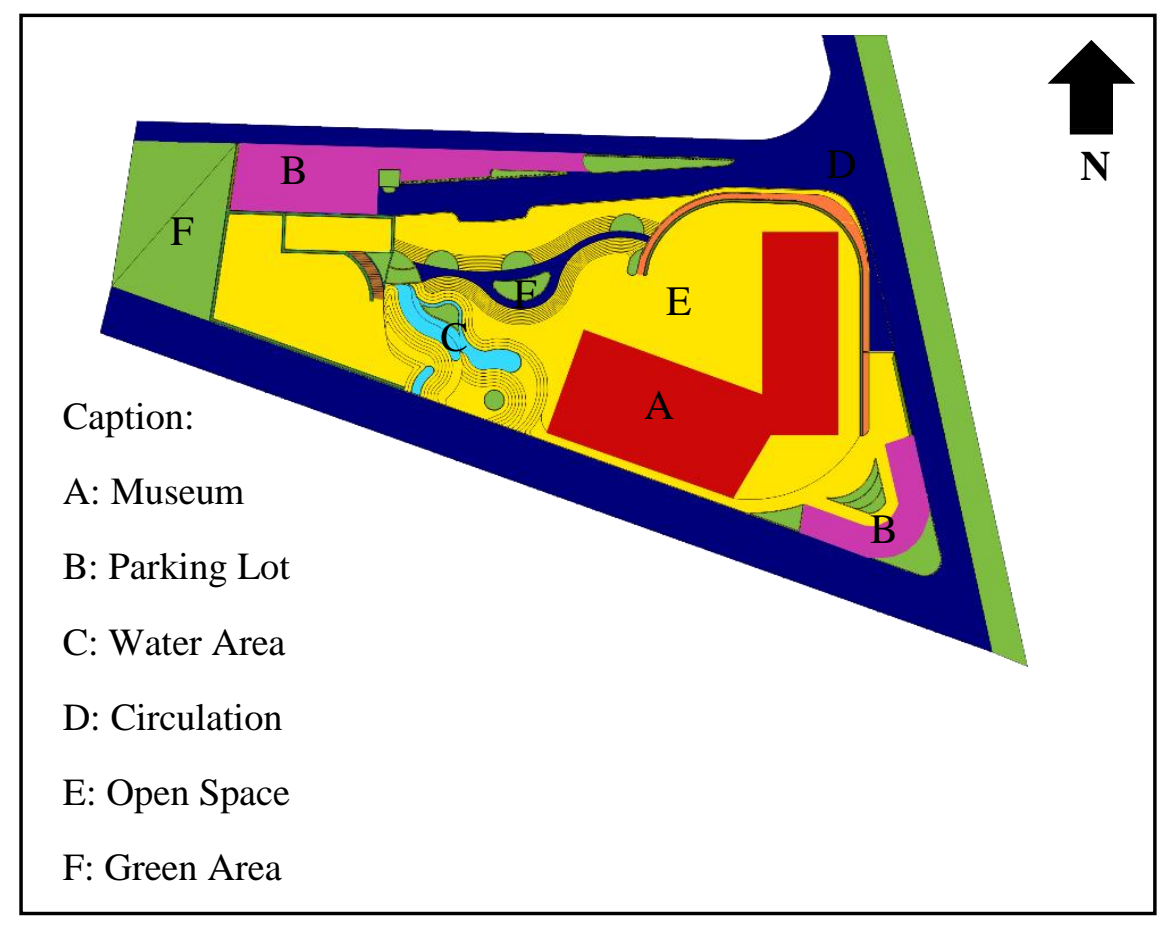

Figure 4. Zoning

\section{Vehicle Circulation Concept}

Car circulation is designed continuously for public parking and also has a different road in services area (Figure 5 and 6). 


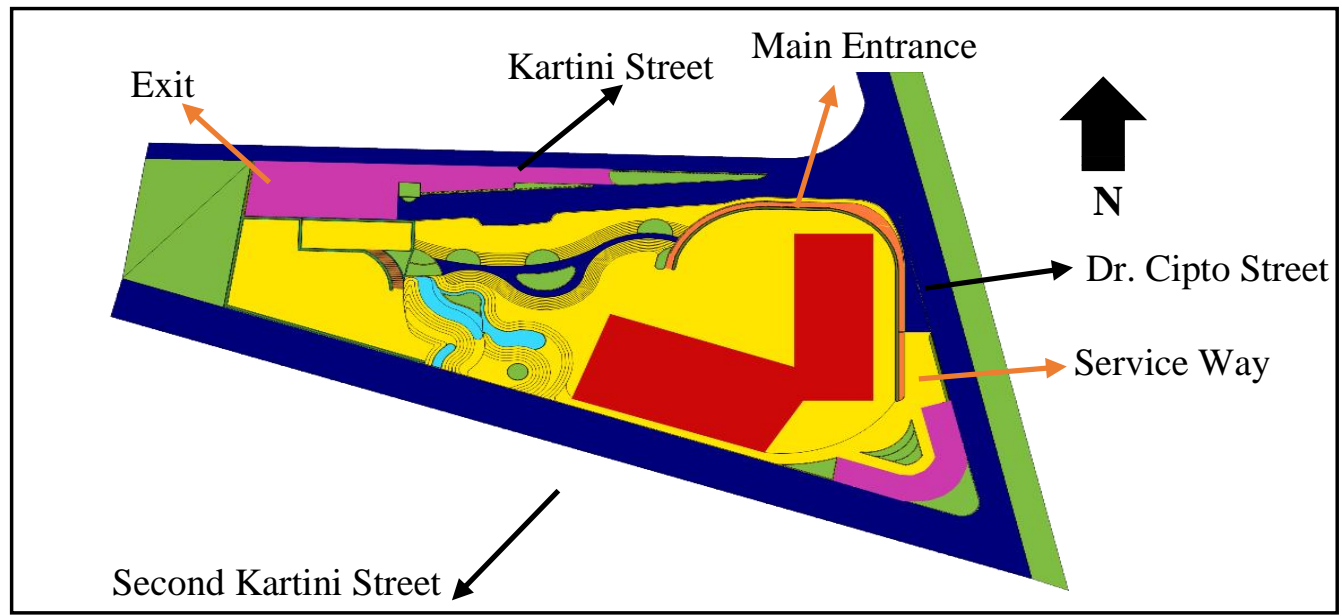

Figure 5. Vehicle Circulation

\section{Exterior Configuration Concept}

The unique topography of the site (sloping) has the potential to be explored further. The elevation of the museum buildings is a result of abstraction of the traditional Nias village system which places the village up on a hill for security reasons from the danger of wild animals and is also a response to the frequent earthquakes and tsunami disaster on the island.

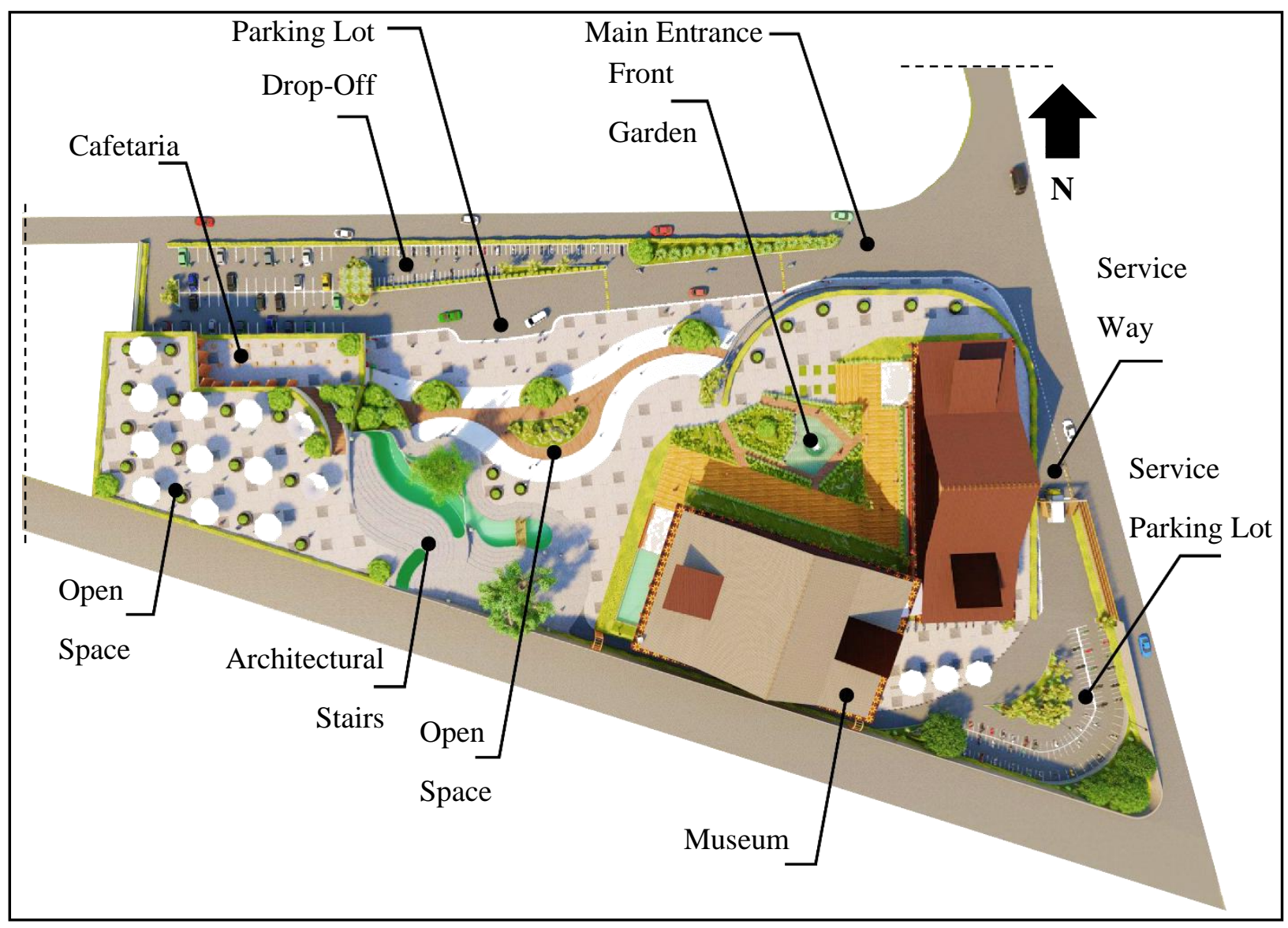

Figure 6. Site Circulation 
Different elevations between the two masses itself have the meaning of earthquake vibration that rise and fall and break the earth's plate, resulting in a form of the ground surface that has various elevations. The placement of museum buildings on different ground levels is the enthusiasm and evidence of the strength of a Nias traditional house that has withstood earthquakes until now. The interpretation of traditional formations is adopted and applied in the design of the outer spatial structure and its relation to the museum building itself as a tribute and education about the local culture.

\section{Mass Concept}

The mass formation of the museum building is the result of inspiration from the custom house of Nias, especially South Nias. Some elements are highlighted in the shape of the roof and the shape of the house on stilts with a typical crossing foundation.

\section{Facade Concept}

The concept of the building facade is derived from a typical abstraction of Nias, especially on the windows of custom houses in the form of wooden grilles. On the facade of the museum building, this grille acts as an ornament as well as secondary skins in the building to filter out the light entering the room and create a certain shadow shape in the interior of the building during the day.

\section{Conclusion}

To answer the goals and benefits that have been set, the conclusions that can be drawn are, a museum design to meet the needs of the community for tourism objects, can have a theme with the object of the exhibition collection that raised important issues that exist today and in the future. Based on the analysis of the results of the design, local wisdom is very risky eroded by the current era of modernization. Architecture can play a role in the education process and continuous recognition through specific work to discuss the issue with space and mass building approach to local wisdom, and in its application, museums can become complex places. With the many types of space available, it will be difficult to set certain limits on space. The concept of sequential space/storyline and special themes (education, etc.), can overcome this and will produce a flow of human movement in the museum to be organized with clear space constraints. 


\section{Acknowledgment}

This research is a study about a museum that intended to give a recommendation to Gunungsitoli City's Government about a solution for tourist object to enhance the city's tourist attraction and make it an icon of Gunungsitoli City.

\section{REFERENCES}

[1] A. Desvales and F. Meiresse, Key Concepts of Museology, Paris: ICOM, 2010.

[2] I. Mentayani and Ikaputra, Menggali Makna Arsitektur Vernakular, Yogyakarta: Universitas Gadjah Mada, 2012.

[3] National Geographic, Nias: Kebangkitan Budaya Negeri Bencana, Jakarta: UNESCO, 2007.

[4] P. J. M. Hammerle, Omo Sebua, Gunungsitoli: Museum Pusaka Nias, 1990. 